\title{
SISTEMA EDUCACIONAL INCLUSIVO: CONCEITO E IMPLICAÇÕES NA POLÍTICA EDUCACIONAL BRASILEIRA
}

\author{
Maria Helena Michels \\ Rosalba Maria Cardoso Garcia ${ }^{*}$
}

RESUMO: A política educacional brasileira vem assumindo uma face "inclusiva", mediada por princípios disseminados em âmbito internacional e pela luta interna em busca de acesso aos direitos sociais. No atual estágio de desenvolvimento da sociedade capitalista faz-se necessário refletir acerca das significações do termo "sistema educacional inclusivo", bem como sobre as implicações políticas de seu uso em meio às contradiçôes sociais. A análise documental e o exame dos microdados (Inep) permitiram perceber sentidos relacionados ao aprofundamento da privatização da educação nacional no uso político do termo "sistema educacional inclusivo". Foram relacionados dados da política de educação especial como expressão da discussão desenvolvida.

Palavras-chave: Sistema educacional. Sistema educacional inclusivo. Política educacional. Educação especial. Microdados.

* Departamento de Estudos Especializados em Educação da Universidade Federal de Santa Catarina (UFSC). Florianópolis (SC) - Brasil.

** Departamento de Estudos Especializados em Educação da Universidade Federal de Santa Catarina (UFSC). Florianópolis (SC) - Brasil.

Contato com as autoras: <mhmichels@uol.com.br>

Cad. Cedes, Campinas, v. 34, n. 93, p. 157-173, maio-ago. 2014

Disponível em <http://www.cedes.unicamp.br> 


\title{
INCLUSIVE EDUCATIONAL SYSTEM: CONCEPT AND IMPLICATIONS FOR THE BRAZILIAN EDUCATIONAL POLICY
}

\begin{abstract}
The Brazilian educational policy has assumed an inclusive face mediated by international principles and by the struggle for social rights. In the current stage of development of the capitalist society it is necessary to reflect upon the meanings of the term "inclusive educational system" as well as the political implications of its use amid social contradictions. The documental analysis and the microdata (Inep) review allowed to realize meanings related to the deepening of the privatization of the national education in the political use of the term "inclusive educational system". Data from the special education policy have been listed as an expression of the discussion developed herein.
\end{abstract}

Key words: Educational system. Inclusive educational system. Educational policy. Special education. Microdata.

\section{Introdução}

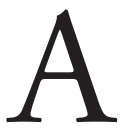

política educacional no Brasil, em consonância com as proposições internacionais para os países em desenvolvimento, assumiu ma perspectiva inclusiva para o setor nas duas últimas décadas. Mais recentemente, notamos o uso do adjetivo "inclusivo" como estratégia para atribuir novos significados ao termo sistema educacional. Observamos que um dos objetivos anunciados no âmbito das políticas de educação inclusiva é transformar o sistema educacional em "sistema educacional inclusivo" (BRASIL, 2005a) No presente artigo assumimos a tarefa de desenvolver uma discussão inicial acerca do conceito e suas possíveis implicações para a política educacional. A investida de análise sobre documentos internacionais e nacionais representativos da política educacional permitiu considerarmos os sentidos presentes na definição do termo "sistema educacional inclusivo", refletirmos sobre o que acrescenta em relação ao termo sistema educacional e ponderarmos a respeito de quais os significados envolvidos no discurso político em foco. Também com o intuito de examinar algumas implicações do uso político do termo, analisamos dados de matrícula da educação especial no Brasil como expressão da política educacional. 


\section{A educação brasileira e a perspectiva inclusiva}

A perspectiva inclusiva na educação "[...] envolve mudanças e modificações no conteúdo, abordagens, estrutura e estratégias, visando abranger todas as crianças na faixa etária adequada e com a convicção que é responsabilidade do sistema regular de ensino educar todas as crianças" (UNESCO, 2003, p. 7).

A mudança de significações parece ser um conteúdo fundamental de tais políticas, a qual também pode ser apreendida pela forma que assumem as expressóes ao analisarmos a incompletude do termo inclusão, que exige sempre e necessariamente um complemento: social, educacional, escolar. Também destacamos o tratamento do termo em foco como adjetivo para mudar questões históricas presentes na sociedade moderna: educação, sistema educacional, currículo, todos agora adjetivados como inclusivos.

Segundo a Organização das Nações Unidas para a Educação, a Ciência e a Cultura (Unesco), existem três justificativas para adotar uma abordagem inclusiva: a primeira tem caráter educacional, a segunda diz respeito ao caráter social e a terceira reflete um motivo econômico.

Primeiro há uma justificativa educacional: a exigência de escolas inclusivas para educar todas as crianças juntas significa que elas têm que desenvolver formas de ensino que respondam às diferenças individuais e que, portanto, beneficiem a todas as crianças. Segundo, há uma justificativa social: escolas inclusivas são capazes de modificar as atitudes em relação à diversidade, educando todas as crianças juntas e formando a base para uma sociedade justa e não discriminatória. Em terceiro lugar, há uma justificativa econômica: é menos oneroso estabelecer e manter escolas que educam todas as crianças juntas que criar um complexo sistema de diferentes tipos de escolas especializadas em diferentes grupos de crianças. (UNESCO, 2009, p. 10)

Já no discurso nacional é possível perceber o atrelamento da política nacional à ideia de "inclusão" como inserção das pessoas na corrente econômica: As políticas inclusivas são "essenciais para a expansão do mercado interno” (BRASIL, 2007a, p. 19).

Observamos a importância do termo inclusão como eixo da política nacional na medida em que passou a integrar os Planos Plurianuais (PPA) a partir do Governo Lula da Silva. No seu primeiro mandato (2003-2006), o PPA 2004-2007 recebeu o título: Orientação estratégica do governo Um Brasil 
Para Todos: crescimento sustentável, emprego e inclusão social. No documento foi possível observar afirmações de inclusão social associadas à desconcentração e redistribuição de renda, redução de desigualdades e operação do consumo de massas. No segundo mandato (2007-2010), o PPA 2008-2011 foi intitulado Desenvolvimento com inclusão social e educação de qualidade. Chama a atenção que um "serviço", tal como a educação é tratada no documento, foi alçado à posição de estratégia principal para promover a inclusão social relacionada à redução das desigualdades, à distribuição de renda, ao desenvolvimento inclusivo e sustentável, focalizando em especial os jovens e as populações pobres. O ponto alto de tais políticas no país, sem dúvida, é o Plano Brasil sem miséria, ${ }^{1}$ que expressa a presença da educação em programas assistenciais de distribuição de renda. No Brasil, nos últimos anos, foram propostas iniciativas visando à ampliação dos índices de matrícula no ensino fundamental e objetivando a universalização do acesso a esse nível de ensino. Mais recentemente, notamos a articulação entre programas de distribuição de renda com o acesso aos programas educacionais, desde a educação infantil, com o lançamento do Programa Brasil Carinhoso, ${ }^{2}$ até a educação profissional, com o Programa Nacional de Acesso ao Ensino Técnico e Emprego (Pronatec). ${ }^{3}$

Educação especial como expressão e estratégia da perspectiva inclusiva

Outro destaque no que se refere à participação das políticas educacionais em iniciativas consideradas "inclusivas" no país diz respeito à educação especial. O termo "inclusão" está presente na legislação do setor desde o início dos anos 2000, mas uma perspectiva de inserção de alunos da educação especial nas escolas de ensino regular, como prevê a Unesco, está manifesta já na LDB n. 9.394/96. Mais recentemente, o documento Politica Nacional de Educação Especial na Perspectiva Inclusiva (BRASIL, 2008) reitera a matrícula de alunos com deficiência, altas habilidades/superdotação e transtorno global do desenvolvimento em escolas regulares. Destacamos que o termo "educação inclusiva" foi apreendido na política educacional brasileira como uma expressão relacionada quase que exclusivamente à educação especial, embora os discursos políticos presentes na documentação internacional não contenham essa interpretação. Em análise da apreensão da Declaração de Salamanca (UNESCO, 1994), Bueno (2008) salienta que o documento teve seu conteúdo alterado no que se refere à tradução de algumas expressões nas versões difundidas no Brasil, 
atribuindo força ao termo "inclusiva” como próprio da educação especial. Na mesma linha das demais políticas de "inclusão" na educação, os alunos da educação especial são o público-alvo de programa de distribuição de renda, mediante o Programa Benefício de Prestação Continuada na Escola (BPC). ${ }^{4}$ Observamos, portanto, que as políticas educacionais "inclusivas" estão orientadas por dois pilares: distribuição de renda e ampliação do número de alunos regularmente matriculados no sistema educacional. Ressalta-se ainda que, recentemente, a educação especial passou a integrar na organização das políticas educacionais a Secretaria de Educação Continuada, Alfabetização, Diversidade e Inclusão (Secadi), a qual congrega a operacionalização da maior parte dos programas educacionais relacionados à distribuição de renda no país. ${ }^{5}$

Ao longo da última década, a política de educação inclusiva relativa à educação especial foi difundida particularmente pelo Programa Educação Inclusiva: direito à diversidade, cujos objetivos referem-se, entre outros, a "efetivar a transformação dos sistemas educacionais em sistemas educacionais inclusivos [...]” (BRASIL, 2005a, p. 9).

\section{Sistema educacional inclusivo: conceito e meta na política}

O termo sistema educacional vem sendo debatido no Brasil, denotando sua complexidade e suas diversas interpretaçôes. Para Saviani (2010, p. 53), "o termo 'sistema' é utilizado em educação de forma equívoca, assumindo, pois, diferentes significados". No intuito de ampliar a compreensão, o autor procura definir melhor o termo como "a unidade de vários elementos intencionalmente reunidos de modo a formar um conjunto coerente e operante" (ibid., p. 44). Por outro lado, Saviani (2008) expõe um conjunto de argumentos conflitivos acerca do sistema educacional, quando analisa a Constituição Federal e a Lei de Diretrizes e bases da Educação Nacional no que se refere à instituição de sistemas de ensino. Tais elementos corroboram sua análise acerca das dificuldades financeiras, políticas, ideológicas e legais de construção de um sistema educacional no Brasil.

[...] é preciso considerar que o conceito de sistema não se resume à ideia de rede de escolas. Para lá dessa acepção, o termo sistema denota um conjunto de atividades que se cumprem tendo em vista determinada finalidade. $\mathrm{E}$ isso implica que as referidas atividades são organizadas 
segundo normas decorrentes dos valores que estão na base da finalidade preconizada. Assim, sistema implica organização sob normas próprias (o que lhe confere um elevado grau de autonomia) e comuns (isto é, que obrigam a todos os seus integrantes). (SAVIANI, 2008, p. 215)

Em meio aos conflitos já existentes em relação ao sistema educacional, percebemos nova ofensiva à educação com o uso do termo "sistema educacional inclusivo", o qual vem sendo notado na documentação nacional (BRASIL, 2000; 2001; 2005a; 2005b; 2008; 2010; 2011) e internacional (UNESCO, 1999; 2000; 2003; 2004; 2009; 2011; BANCO MUNDIAL, 2011) representativas da política educacional, gerando algumas questôes. Quais os sentidos que estão sendo mobilizados em tais discursos? Qual a lógica discursiva ali implicada? Por que é necessário adjetivar o sistema educacional?

Nos últimos anos, as políticas de perspectiva inclusiva retomaram com novas feições a incorporação de "todos" no sistema educacional. Discussões propostas a partir da Conferência Mundial de Educação para Todos (1990) e da Conferência Mundial sobre Necessidades Especiais (1994) inseriram no debate político a necessidade de os sistemas educacionais serem reformulados para acolher todas as crianças e jovens na faixa etária adequada à educação básica. Tais reformulaçôes diziam respeito à ampliação do acesso e da permanência na escola de ensino regular, a redução dos índices de repetência e evasão, de recrutamento e formação de professores voltados ao trabalho com a diversidade humana (UNESCO, 1990; 1994). Particularmente em relação ao público-alvo das políticas de educação especial, os organismos internacionais passaram a difundir a ideia de não discriminação educacional pela condição de deficiência (ONU, 2006) e a necessidade de incorporar aos sistemas educacionais recursos específicos para atender às necessidades de aprendizagem dos estudantes com deficiência (UNESCO, 1994; 1999). Houve, desde então, um acento na difusão da ideia segundo a qual "todos" deveriam estudar juntos, frequentar as mesmas escolas, romper com a existência de dois "sistemas" de ensino constituídos por uma rede de escolas regulares e uma rede paralela de instituições de educação especial.

Tais proposiçōes elegeram como ponto central a ser enfrentado o fenômeno definido como "exclusão social" e sua face educacional. Incorporando "todos" ao sistema educacional estaríamos desenvolvendo uma "educação inclusiva", cujo efeito mais amplo, segundo os discursos 
oficiais, seria promover uma "sociedade inclusiva". Para tanto, as políticas educacionais, em grande medida aquelas voltadas à educação especial, deveriam contribuir para "transformar" o sistema educacional em sistema educacional inclusivo (UNESCO, 1999; BRASIL, 2005a; 2010).

A leitura de tais proposições permite perceber a linearidade de pensamento ao relacionar como causa e efeito o binômio exclusão/inclusão e o conservadorismo da proposta que deposita na educação o papel redentor de solucionar as questões sociais. É possível notar que o debate em torno da sociedade e da educação é desenvolvido mediante um silenciamento das relações sociais que presidem o tempo presente. Aquilo que, de início, parece ser a redenção de grupos excluídos historicamente do acesso ao conhecimento, à instrução e à cultura humana, nas relações sociais vigentes acaba por concretizar-se em formação das massas para o trabalho simples. Ramos esclarece a relação trabalho/conhecimento a respeito da divisão (internacional) do trabalho:

[O] parcelamento reduz a complexidade da produção de uma mercadoria ou de um serviço completos - o trabalho complexo - ao conjunto de tarefas simples destinadas a produzir as respectivas partes. Por isto, do trabalhador não são exigidos mais conhecimentos do que aqueles estritamente necessários para realizar operaçóes simples e para proporcionar uma adaptação psicofísica a essa nova forma de dividir o trabalho. [...] O trabalho simples, portanto, é aquele reduzido à indiferença de quem o realiza, já que, para isto, não são exigidos mais do que conhecimentos elementares, como ler, escrever e contar, além de rudimentos técnicoprocedimentais para o exercício das tarefas. (RAMOS, 2007, p. 41)

No âmbito de tais propostas, expomos a crítica apresentada pelo Banco Mundial ao sistema educacional "tradicional":

O termo "sistema educacional" refere-se tipicamente às escolas públicas, universidades e programas de formação que fornecem serviços de educação. Nesta estratégia, "sistema educacional" inclui a gama completa de oportunidades de aprendizagem que existem num país, quer sejam fornecidas ou financiadas pelo sector público, quer privado (incluindo organizações religiosas, organizações sem fins lucrativos ou com fins de lucro). Inclui programas formais ou não formais, para além de toda a gama de beneficiários e interessados nestes programas: professores, formadores, administradores, funcionários, estudantes e as suas famílias e empregadores. Inclui também as regras, políticas e mecanismos de 
responsabilização que aglutinam um sistema de educação, bem como os recursos e mecanismos de financiamento que o sustentam. Este conceito mais inclusivo do sistema educacional permite ao Grupo do Banco e aos países parceiros aproveitar as oportunidades e eliminar as barreiras que se situam fora dos limites do sistema tal como ele é tradicionalmente definido. (BANCO MUNDIAL, 2011, p. 5)

Vejamos algumas reflexões a partir da proposta do Banco Mundial. Em primeiro lugar, os "sistemas educacionais" caracterizam-se por uma malha de instituições públicas. O "sistema educacional inclusivo" amplia a malha institucional para o setor privado. Em segundo lugar, os "sistemas educacionais", via de regra, funcionam mediante a oferta de programas formais de educação. O "sistema educacional inclusivo" expande para programas não formais. Compreende-se que, na perspectiva defendida pelo Banco Mundial, o "sistema educacional", tal como é "tradicionalmente definido", limita a oferta, agora ampliada por um "conceito mais inclusivo". Podemos perceber no excerto destacado a defesa da educação como um negócio, um componente fundamental do mercado e regido por suas regras, concebida como uma "oportunidade" à medida que as "barreiras" do sistema público são "eliminadas".

Podemos concluir que o discurso que defende a transformação do sistema educacional em "sistema educacional inclusivo" refere-se menos a democratizar o acesso à educação e muito mais a aprofundar a presença de uma lógica privatista na educação.

Por um lado, a educação como negócio "elimina as barreiras" para a entrada de empresas que comercializam "sistemas de ensino". Estudos (ARELARO, 2007; ADRIÃO et al., 2009; 2010) têm mostrado a compra e venda de propostas curriculares, materiais didáticos e treinamento de professores na educação básica no Brasil. ${ }^{6}$

Por outro lado, a gestão da educação pela lógica do privado amplia as "oportunidades" para as parcerias público-privado na educação, alimentando a entrada no sistema educacional de organizações não governamentais (MONTAÑO; DURIGUETTO, 2011). Tais parcerias assumem a forma de convênios (PERONI et al., 2009), os quais têm sido observados como mais presentes na educação infantil e na educação especial.

Se, por um lado, o termo "sistema educacional inclusivo" remete para a ampliação dos direitos e inserção social de grupos historicamente marginalizados, por outro lado, mobiliza sentidos pouco explicitados de 
incorporação de uma lógica privatista na educação estruturada em dois grandes eixos: o privado mercantil e o privado assistencial.

Tal conclusão remete para uma segunda percepção segundo a qual o termo "inclusão", relacionado à educação, vem sendo divulgado como um elemento fundamental para o crescimento econômico. Para tanto, são necessários "sistemas educacionais inclusivos, holísticos e equilibrados" (UNESCO, 2011, p. 16). Segundo a Unesco, mudanças nos sistemas educacionais nos diferentes países, de modo a torná-los “inclusivos”, produzem sociedades menos suscetíveis a conflitos violentos (ibid., p. 24). $\mathrm{O}$ projeto educacional em questão consiste no amplo atendimento da população em idade escolar obrigatória das camadas mais empobrecidas, retirando crianças e jovens das ruas e buscando arregimentá-los para o trabalho simples.

Outro elemento a ser destacado em relação ao "sistema educacional inclusivo" é que a lógica privatista atinge fortemente a gestão do sistema educacional. A reforma do Estado brasileiro, na década de 1990, instituiu uma lógica gerencial para a educação nacional (BRESSER PEREIRA, 1996). A partir daí, novas formas de sistematização da educação escolar passaram a ser difundidas nas redes de ensino. Como exemplo de uma nova sistematização na operacionalização da educação básica, podemos mencionar o Plano de Ações Articuladas, gerado a partir do Plano de Desenvolvimento da Educação - PDE (BRASIL, 2007b) e que visa o cumprimento das metas do Compromisso Todos pela Educação (BRASIL, 2008). Como forma de desenvolver tais compromissos, foi criado o PDE Escola - Plano de Desenvolvimento da Escola, programa de acompanhamento da gestão e financiamento das escolas públicas. ${ }^{7}$ Outra expressão de uma nova sistematização operacional da educação é o Sistema Integrado de Monitoramento, Execução e Controle (Simec) do Ministério da Educação, um portal operacional e de gestão do MEC, que trata do orçamento e monitoramento das propostas on-line do governo federal na área da educação.

São mudanças na gestão do sistema que remetem à reforma do Estado brasileiro, a partir da década de 1990, para racionalizar as atividades estatais com modificações na sua estrutura e no seu modus operandi segundo a lógica do mercado (KRAWCZIK, 2008).

Mais que ampliar e aprofundar questões acerca do sistema educacional, a noção de "sistema educacional inclusivo" difundida carrega uma perspectiva de gerenciamento da educação, mediante "sistemas" operacionais 
de controle financeiro e administrativo, sobre o trabalho docente e sobre o rendimento escolar dos estudantes, por meio da mensuração de índices educacionais. Percebe-se que uma das implicações de tal perspectiva é a crescente homogeneização da educação escolar em patamares básicos de ensino.

Implicações da lógica privatista na política de educação especial, na perspectiva inclusiva, no Brasil

Para apreender as implicações de uma lógica "inclusiva” e de seu caráter privatista, vamos apresentar e analisar dados de matrícula da educação especial por dependência administrativa a partir dos microdados do Inep.

Os dados foram agrupados nas categorias público e privado, considerando como público as matrículas nas dependências estaduais e municipais e como privado as categorias particular, comunitária, confessional e filantrópica, entre os anos de 2007 e $2012 .^{8}$

Observamos, conforme a Tabela 1 , a manutenção do padrão de predomínio de percentuais de matrículas da educação especial brasileira nas instituições privadas nos anos analisados. Além disso, notamos que houve no período analisado uma tendência de crescimento dos percentuais de matrículas no setor privado de 63,81 em 2007 para 71,10 em 2012.

\section{Tabela 1}

Matrículas da educação especial - Brasil (2007-2010):

por dependência administrativa

\begin{tabular}{c|c|c|c|c|c}
\hline \multirow{2}{*}{ Ano } & \multirow{2}{*}{ Total de matrícula } & \multicolumn{2}{|c|}{ Público } & \multicolumn{2}{c}{ Privado } \\
\cline { 3 - 6 } & & Matrícula & Percentual & Matrícula & Percentual \\
\hline 2007 & 352.245 & 127.475 & 36,19 & 224.770 & 63,81 \\
2008 & 330.074 & 115.585 & 35,02 & 214.489 & 64,98 \\
2009 & 251.463 & 88.327 & 35,13 & 163.136 & 64,87 \\
2010 & 217.459 & 74.572 & 34,30 & 142.887 & 65,70 \\
2011 & 183.820 & 53.022 & 28,84 & 130.798 & 71,15 \\
2012 & 198.907 & 57.476 & 28,89 & 141.431 & 71,10 \\
\hline
\end{tabular}

Fonte: Elaboração própria com base nos microdados do Inep (2007, 2008, 2009, 2010, 2011, 2012). 
Tais dados permitem afirmar que o período de vigência de uma política de perspectiva inclusiva para a educação especial no Brasil não representou mudança no quadro de oferta predominante no setor privado, corroborando com as análises aqui apresentadas, segundo as quais a perspectiva inclusiva revela-se integrante das estratégias de aprofundamento da privatização na educação.

Tomando o estado de Santa Catarina como referência de análise, os dados são ainda mais contundentes ao indicarem que, no período de 2007-2012, as taxas de matrículas nas instituições privadas denotam índices superiores aos nacionais em cinco dos seis anos examinados. Enquanto a média percentual nacional de matrículas da educação especial no setor privado é de 66,93\%, em Santa Catarina é de $84,65 \%$ no mesmo período.

\section{Tabela 2}

Matrículas da educação especial - Santa Catarina (2007-2010): por dependência

\begin{tabular}{c|c|c|c|c|c}
\hline \multirow{2}{*}{ Ano } & \multirow{2}{*}{ Total de matrícula } & \multicolumn{2}{|c|}{ Público } & \multicolumn{2}{c}{ Privado } \\
\cline { 3 - 6 } & & Matrícula & Percentual & Matrícula & Percentual \\
\hline 2007 & 17.442 & 1.561 & 8,95 & 15.881 & 91,05 \\
2008 & 17.296 & 1.490 & 8,62 & 15.806 & 91,38 \\
2009 & 1.263 & 465 & 36,82 & 798 & 63,18 \\
2010 & 1.348 & 241 & 17,87 & 1.107 & 82,13 \\
2011 & 1.369 & 158 & 11,54 & 1.211 & 88,45 \\
2012 & 1.295 & 107 & 8,26 & 1.188 & 91,73 \\
\hline
\end{tabular}

Fonte: Elaboração própria com base nos microdados do Inep (2007, 2008, 2009, 2010, 2011, 2012).

É possível observarmos, portanto, a ampla participação do setor privado na oferta de educação especial, com destaque para o privado filantrópico. Com base em dados de 2012, em Santa Catarina, verificamos 1.188 matrículas no setor privado, das quais $1.012 \mathrm{em}$ instituições filantrópicas, representando $85,18 \%$. Tais dados sugerem a manutenção no setor da importante presença de instituições mantidas pelas Associações de Pais e Amigos dos Excepcionais (APAEs) no estado, as quais estão 
presentes em 195 dos 297 municípios de Santa Catarina, segundo dados da Federação Estadual das APAEs.

\section{Considerações finais}

A perspectiva inclusiva na educação no Brasil vem assumindo, por um lado, uma face democratizante, embora garantindo o reconhecimento do direito à educação de maneira subalterna, com vistas ao trabalho simples. Por outro lado, carrega sentidos humanitários quando promove ideologicamente o pertencimento ao sistema educacional e o acesso a padrôes mínimos de renda. Tais elementos têm servido de combustível para a aceitação social de uma ofensiva privatista sobre a educação brasileira.

A educação especial, que se constituiu historicamente com importante atuação do setor privado assistencial, não apresenta transformações relevantes nesse aspecto, conforme os microdados aqui analisados.

O uso político do termo "sistema educacional inclusivo" não tem sobressaído como elemento de aprofundamento dos debates acerca do sistema educacional. Ao contrário, tem favorecido o acirramento dos equívocos já existentes sobre o tema. Entretanto, contribui sobremaneira para lançar luz nas relações entre os setores públicos e privados, como uma aliança liberal de todas as forças sociais para resolver as questóes educacionais. Sobressai, nesse caso, o esforço do capital para adentrar todos os setores da sociedade, inclusive a educação, buscando transformá-la também em objeto do mercado.

O termo "sistema educacional inclusivo" vem carrear sentidos de valorização do setor privado na educação, nas suas faces mercantil e assistencial. Também confunde a noção de sistema educacional com a proposição de sistemas operacionais de gestão e controle da educação nacional, apresentados com uma aura de eficiência e transparência na distribuição dos recursos financeiros.

As reflexões aqui apresentadas buscaram contribuir com a produção de um pensamento crítico em relação às políticas educacionais. Particularmente em relação à educação das pessoas com deficiência, continuamos advogando pela sua incorporação a práticas sociais que visem o desenvolvimento humano, em suas formas mais elevadas, e colocamo-nos na recusa em aceitar seu envolvimento em estratégias que buscam forjar na sociedade capitalista uma face eminentemente humana. 


\section{Notas}

1. Constituído por um conjunto de programas, como o Bolsa Família, a Previdência Rural, o Brasil Alfabetizado, o Saúde da Família, o Brasil Sorridente, o Mais Educação e a Rede Cegonha.

2. Ampliação do Programa Bolsa Família para crianças até 6 anos e 11 meses de idade.

3. Criado no dia 26 de outubro de 2011 pela Lei n. 12.513/2011. Disponível em: <http://pronatec. mec.gov.br>

4. Programa de Acompanhamento e Monitoramento do Acesso e Permanência na Escola das Pessoas com Deficiência Beneficiárias do Benefício de Prestação Continuada (BPC), instituído pela Portaria Normativa Interministerial n. 18, de 24 de abril de 2007. Disponível em: <http:// www.mds.gov.br/assistenciasocial/redesuas/arquivos/2011/legislacao>

5. A Secretaria de Educação Especial (SEE-SP) foi extinta pelo Decreto n. 7.480, de 16 de maio de 2011. O setor agora conta com uma Diretoria de Políticas de Educação Especial (DPEE) na Secretaria de Educação Continuada, Alfabetização, Diversidade e Inclusão (Secadi).

6. Dentre as "marcas" mais conhecidas no país podemos destacar "COC", "Objetivo", "Anglo", "Positivo".

7. O PDE Escola utiliza a plataforma ou "sistema" denominado PDE Interativo.

8. Particular - mantida por uma ou mais pessoas físicas ou jurídicas de direito privado, com fins lucrativos; Comunitária - mantida por grupo de pessoas físicas ou por uma ou mais pessoas jurídicas, inclusive cooperativas educacionais, e inclui representantes da comunidade na mantenedora. Sem fins lucrativos; Confessional - instituída por grupo de pessoas físicas, ou por uma ou mais pessoas jurídicas que atendam à orientação confessional e ideológica específica, e que inclua, na sua entidade mantenedora, representantes da comunidade; Filantrópica - mantida por grupo de pessoas físicas ou jurídicas com a finalidade de oferecer escolarização e/ou apoio pedagógico gratuito à população carente. Sem fins lucrativos (BRASIL, 2009, p. 11).

\section{Referências}

ADRIÃO, T. et al. Uma modalidade peculiar de privatização de educação pública: a aquisição de sistemas de ensino por municípios paulistas. Educação \& Sociedade, Campinas, v. 30, n. 108, p.799-818, out. 2009. Disponível em: <http://www.scielo.br/?ing=pt>. Acesso em: 25 out. 2012.

ADRIÃO, T. et al. Simbiose entre as prefeituras paulistas e o setor privado: tendências e implicações para a política educacional local. In: REUNIÃO ANUAL DA ANPEd, 33., 2010, Caxambú. Anais... Caxambú, 2010. Disponível em: <http://33reuniao.anped.org.br/>. Acesso em: 28 set. 2012.

ARELARO, L. Formulação e implementação das políticas públicas em educação e as parcerias público-privadas: impasse democrático ou

Disponível em <http://www.cedes.unicamp.br> 
Sistema educacional inclusivo: conceito e implicações na política educacional brasileira

mistificação política? Educação \& Sociedade, Campinas, v. 28, n. 100, p. 899-919, out. 2007.

BANCO MUNDIAL. Aprendizagem para todos: investir nos conhecimentos e competências das pessoas para promover o desenvolvimento; estratégia 2020 para a educação do Grupo Banco Mundial; resumo executivo. Washington, DC: Banco Mundial, 2011. 16p.

BRASIL. Decreto n. 7.083, de 27 de janeiro de 2010. Dispóe sobre o Programa Mais Educação. Diário Oficial da União, Brasília, DF, 27 jan. 2010. Seção 1, Edição extra, p. 2. Disponível em: <http://www.planalto.gov.br/ ccivil_03/_ato2007-2010/decreto/d7083.htm>. Acesso em: 10 dez. 2013.

BRASIL. Decreto n. 7.611, de 17 de novembro de 2011. Dispóe sobre a educação especial, o atendimento educacional especializado e dá outras providências. Diário Oficial da União, Brasília, DF, 18 nov 2011. Edição Extra, p. 12. Disponível em: <http://www.planalto.gov.br/ccivil_03/_ ato2011-2014/2011/decreto/d7611.htm>. Acesso em: 15 mar. 2012.

BRASIL. Ministério da Educação. Conselho Nacional da Educação. Câmara de Educação Básica. Parecer n. 17, de 3 de julho de 2001. Diretrizes Nacionais para a Educação Especial na Educação Básica. Diário Oficial da União, Brasília, DF, 17 ago. 2001. Seção 1, p. 46. Disponível em: <http: //www.portal.mec.gov.br/seesp/arquivos/pdf/parecer17.pdf>. Acesso em: 15 mar. 2002.

BRASIL. Ministério da Educação. Instituto Nacional de Estudos e Pesquisas Educacionais Anísio Teixeira (INEP). Censo Escolar Educacenso: caderno de instruçôes. Brasília, DF: MEC/ Inep, 2009.

BRASIL. Ministério da Educação. Secretaria de Educação Especial. Projeto Escola Viva: garantindo o acesso e permanência de todos os alunos na escola; alunos com necessidades educacionais especiais. Brasília, DF: MEC/SEESP, 2000. (Construindo a escola inclusiva, n. 4). Disponível em: <http://www.mec.gov.br>. Acesso em: 21 out. 2001.

BRASIL. Ministério da Educação. Secretaria de Educação Especial. Programa Educação Inclusiva: direito à diversidade. Brasília, DF: MEC/ SEESP, 2005a. (Documento orientador). Disponível em: <http://www. mec.gov.br>. Acesso em: 12 abr. 2006. 
BRASIL. Ministério da Educação. Secretaria de Educação Especial. Saberes e práticas de inclusão: recomendações para a construção de escolas inclusivas. Brasília, DF: MEC/SEESP, 2005b. Disponível em: <htpp:// www.mec.gov.br>. Acesso em: 19 nov. 2005.

BRASIL. Ministério da Educação. O Plano de Desenvolvimento da Educação: razões, princípios e programas. Brasília, DF: MEC, $2007 \mathrm{~b}$.

BRASIL. Ministério do Planejamento, Orçamento e Gestão. Secretaria de Planejamento e Investimentos Estratégicos. Plano plurianual 20082011: projeto de lei / Ministério do Planejamento, Orçamento e Gestão, Secretaria de Planejamento e Investimentos Estratégicos. Brasília, DF: MP, 2007a. 540p.; v.2.

BRASIL. Ministério da Educação. Secretaria de Educação Especial. Política Nacional de Educação Especial na perspectiva inclusiva. Brasília, DF: MEC/SEESP, 2008. Disponível em: <http://www.mec.gov.br>. Acesso em: 21 dez. 2008.

BRESSER PEREIRA, L.C. Da administração pública burocrática à gerencial. Revista do Serviço Público, Brasília, DF, v. 47, n. 1, jan./abr. 1996. Disponível em: <http://blogs.al.ce.gov.br/unipace/files/2011/11/ Bresser1.pdf>. Acesso em: 10 abr. 2002.

BUENO, J.G.S. As políticas de inclusão escolar: uma prerrogativa da educação especial? In: BUENO, J.G.S.; MENDES, G.M.L.; SANTOS, R.A. (Org.). Deficiência e escolarização: novas perspectivas de análise. Araraquara: Junqueira \& Marin; Brasília, DF: Capes, 2008. p. 43-63.

CONFERENCIA NACIONAL DE EDUCAÇÃO (CONAE), 2010, Brasília, DF. Construindo o sistema nacional articulado de educação: o Plano Nacional de Educação, diretrizes e estratégias de ação. Brasília, DF: Conae, 2010. (Documento referência).

KRAWCZYK, N.R. PDE: o novo modo de regulação estatal? Cadernos de Pesquisa, São Paulo, v. 38, n. 135, p. 797-815, set./dez. 2008. Disponível em: <http://www.scielo.br/pdf/cp/v38n135/v38n135a11.pdf>. Acesso em: 2 mar. 2009.

MONTAÑO, C.; DURIGUETTO, M.L. Estado, classe e movimento social. 3. ed. São Paulo: Cortez, 2011. 
Sistema educacional inclusivo: conceito e implicações na política educacional brasileira

ORGANIZAÇÃO DAS NAÇÕES UNIDAS (ONU). Convenção sobre os direitos das pessoas com deficiência. New York, 2006. Disponível em: <http:// www.un.org/disabilities/default.asp?id=150>. Acesso em: 4 maio 2008.

PERONI, V.P.V. et al. Estado e terceiro setor: as novas regulações entre o público e o privado na gestão da educação básica brasileira. Educação \& Sociedade, Campinas, v. 30, n. 108, p. 761-778, 2009. Disponível em: <http://www.scielo.br/pdf/es/v30n108/a0730108.pdf>. Acesso em: 9 ago. 2010.

RAMOS, M.N. Conceitos básicos sobre o trabalho. In: FONSECA, A.F. (Org.). O processo histórico do trabalho em saúde. Rio de Janeiro: EPSJV; Fiocruz, 2007. p. 27-56.

SAVIANI, D. Desafios da construção de um sistema nacional articulado de educação. Trabalho, Educação \& Saúde, Rio de Janeiro, v. 6, n. 2, p. 213-231, jul./out. 2008.

SAVIANI, D. Sistema de Educação: subsídios para a Conferência Nacional de Educação; o impacto das propostas dos movimentos sindicais e sociais na Conferência Nacional de Educação. Curitiba: CNTE, 2010. p. 41-69

TODOS PELA EDUCAÇĀO: rumo a 2022. [S.l: s.n.], 2006. Disponível em: <http://www.todospelaeducacao.org.br/biblioteca.aspx>. Acesso em: 15 mar. 2009.

UNESCO. Salamanca cinco años después: una revision de las actividades de la Unesco a la luz de la declaración de Salamanca. Paris, 1999.

UNESCO. Forum Mundial sobre a Educação: marco de ação; cumprir nossos compromissos comuns. Dakar, Senegal, 2000.

UNESCO. Declaração de Salamanca: sobre princípios, políticas e práticas na área das necessidades educativas especiais. Salamanca, 1994. Disponível em: <http://portal.mec.gov.br/seesp/arquivos/pdf/salamanca.pdf>. Acesso em: 10 set. 2011.

UNESCO. Overcoming exclusion thought inclusive approaches in education: a challenge and a vision; conceptual paper. Paris, 2003. Disponível em: $<$ http://unesdoc.unesco.org/images/0013/001347/134785e.pdf>. Acesso em: 25 jun. 2005. 
UNESCO. Temário abierto sobre educación inclusiva: materiales de apoyo para responsables de políticas educativas. Santiago, 2004. Disponível em: <http://unesdoc.unesco.org/images/0012/001252/125237so.pdf>. Acesso em: 5 abr. 2005.

UNESCO. Policy guidelines on inclusion in education. Paris, 2009. Disponível em: <http://unesdoc.unesco.org/images/0017/001778/177849e. pdf>. Acesso em: 4 mar. 2012.

UNESCO. Unesco and education: everyone has the right to education. Paris, 2011. Disponível em: <http://unesdoc.unesco.org/ images/0021/002127/212715e.pdf>. Acesso em: 8 mar. 2012.

Recebido em fevereiro de 2014.

Aprovado em maio de 2014. 